\section{SOSIALISASI \\ PENTINGNYA CRITICAL THINKING UNTUK MEMBANGUN GENERASI MUDA YANG KRITIS DALAM KEGIATAN LATIHAN DASAR KEPEMIMPINAN SISWA SMA CITRA ISLAMI CIKUPA}

Isnaini Mahuda ${ }^{*}$, Miftahul Huda ${ }^{2}$

1, 2 Program Studi Statistika, Fakultas Sains dan Teknologi, Universitas Bina Bangsa

* Isnaini Mahuda

Email: isnaini.mahuda@binabangsa.ac.id

\begin{abstract}
Critical thinking is one of the abilities that every individual must possess in order to be able to adapt to increasingly complex life. This critical thinking ability is also crucial for every leader to support the proper analysis and decision making. As the young generation of future leaders, students need this critical thinking ability. Therefore, socialization was carried out regarding the importance of critical thinking to build a critical young generation. This Community Service Activity is a series of Student Leadership Basic Training activities at SMA Citra Islami Cikupa. The socialization process was carried out by giving lectures and discussions with the activity participants and a questionnaire evaluation. The results of this Community Service activity provide conclusions including I) socialization about the importance of critical thinking skills or critical thinking goes well and is followed with great enthusiasm by prospective student council administrators; 2) this socialization is also a provision for prospective student council administrators as the young generation of future leaders to continue to hone their critical skills. Keywords: critical thinking; leader; critical
\end{abstract}

\begin{abstract}
Abstrak
Critical thinking atau berpikir kritis menjadi salah satu kemampuan yang wajib dimiliki oleh setiap individu agar mampu beradaptasi dalam kehidupan yang semakin kompleks. Kemampuan bepikir kritis ini juga penting untuk dimiliki oleh setiap pemimpin guna mendukung analisis dan pengambilan keputusan yang tepat. Para siswa/i sebagai generasi muda calon pemimpin masa depan membutuhkan kemampuan berpikir kritis ini. Oleh karena itu dilakukan sosialisasi mengenai pentingnya critical thinking untuk membangun genarasi muda yang kritis. Kegiatan Pengabdian Kepada Masyarakat ini merupakan rangkaian dari kegiatan Latihan Dasar Kepemimpinan Siswa (LDKS) SMA Citra Islami Cikupa. Proses sosialisasi dilakukan dengan cara memberikan ceramah dan diskusi dengan para peserta kegiatan dan diakhiri dengan evaluasi menggunakan angket. Adapun hasil dari kegiatan Pengabdian kepada Masyarakat ini memberikan kesimpulan diantaranya yaitu: I) sosialisasi mengenai pentingnya kemampuan berpikir kritis atau critical thinking berjalan dengan baik dan diikuti dengan sangat antusias oleh para siswa/i calon pengurus OSIS; 2) sosialisasi ini juga menjadi bekal bagi para siswa/i calon pengurus OSIS sebagai generasi muda calon pemimpin masa depan untuk terus mengasah kemampuan kritisnya.
\end{abstract}

Kata Kunci: critical thinking; pemimpin; kritis 
Sosialisasi Pentingnya Critical Thinking untuk Membangun Generasi Muda yang Kritis dalam kegiatan Latihan Dasar Kepemimpinan Siswa SMA Citra Islami Cikupa

Isnaini Mahuda' Miftahul Huda

Volume 1, No. 3, Desember 2021 hal. 210-215

DOI Artikel: 10.46306/jub.v1i3.38

\section{PENDAHULUAN}

Di era disruptif sekarang ini tanpa disadari banyak sekali perubahan yang terjadi akibat berkembangnya Teknologi Informasi dan Komunikasi (TIK). Dalam situsasi tersebut menuntut adaptabilitas setiap individu untuk menghadapi tantangan sekaligus ancaman yang semakin kompleks hampir disetiap bidang kehidupan. Kemampuan berfikir kritis atau critical thinking menjadi suatu kebutuhan dasar yang harus dimiliki oleh setiap individu agar mampu beradaptasi dalam perkembangan zaman. Kemampuan berpikir kritis juga menjadi salah satu keterampilan yang perlu dimiliki di tahun 2020 sebagaimana dijelaskan dalam World Economic Forum. Berpikir kritis merupakan proses berpikir yang melibatkan pengambilan keputusan berdasarkan alasan-alasan tertentu dan mempunyai suatu kecenderungan untuk dapat mempengaruhi orang lain atas apa yang harus diterima sebagai sebuah kebenaran (Bassham et al, 20I I, p. I). Dengan kemampuan berpikir kritis tersebut seseorang akan mampu mengambil keputusan berdasarkan alasan alasan yang logis dan terstuktur.

Generasi muda saat ini atau yang dikenal sebagai generasi milenial adalah calon pemimpin di masa depan. Untuk dapat menjadi seorang pemimpin yang baik dibutuhkan karakter, sifat dan juga keterampilan yang perlu ditanamkan sedini mungkin. Salah satu bentuk kegiatan di sekolah yang menyajikan konsepkonsep dasar organisasi dan kepemimpinan dalam diri siswa yaitu latihan dasar kepemimpinan siswa atau LDKS. Latihan ini bertujuan untuk menumbuhkan jiwa kepemimpinan dalam diri siswa dan diharapkan melalui kegiatan ini para siswa dapat memiliki karakteristik seorang pemimpin yaitu memiliki intelektual, kreatifititas serta nalar berfikir yang benar.

Kemampuan berpikir kritis atau critical thinking penting dimiliki oleh setiap pemimpin. Seorang pemimpin yang memiliki kemampuan berpikir kritis dapat memahami hubungan logis antara ide, argument atau kesalahan dalam penalaran sehingga bisa membuat keputusan yang tepat (Wicaksono, 202I). Seperti yang dijelaskan pula oleh Patterson (20II) bahwa berpikir kritis itu memanfaatkan informasi yang logis sebagai dasar pemikiran. Sehingga kemampuan bepikir kritis ini penting guna mendukung analisis dan pengambilan keputusan yang tepat bagi seorang pemimpin. Selain itu, Wahyuni (2016) menerangkan bahwa kemampuan berpikir kritis sangatlah penting dalam membantu siswa untuk mengembangkan dan meningkatkan bakatnya, salah satunya yaitu bakat kepemimpinan.

\section{METODE PENGABDIAN}

Metode yang digunakan dalam Kegiatan Pengabdian kepada Masyarakat ini terdiri 5 (lima) tahapan diantaranya yaitu:

I) Survey lapangan

Pada tahapan ini tim melakukan survey ke sekolah tempat dilakukannya kegiatan yaitu SMA Citra Islami Cikupa. Tim berkoordinasi dengan panitia LDKS baik itu dari jajaran siswa maupun para guru yang terlibat dan membahas mengenai tema yang akan diangkat. 
Sosialisasi Pentingnya Critical Thinking untuk Membangun Generasi Muda yang Kritis dalam kegiatan Latihan Dasar Kepemimpinan Siswa SMA Citra Islami Cikupa

Isnaini Mahuda' Miftahul Huda

Volume 1, No. 3, Desember 2021 hal. 210-215

DOI Artikel: 10.46306/jub.v1i3.38

2) Persiapan pelaksanaan

Tim menyiapkan materi dengan cara mengumpulkan informasi dari beberapa sumber referensi serta menyiapkan kelengkapan yang akan dipergunakan selama kegiatan.

3) Sosialisasi

Tim yang diwakili oleh narasumber memberikan sosialisasi dengan tema "Pentingnya Critical Thinking dalam Membangun Generasi Muda yang Kritis" melalui ceramah bervariasi untuk menyampaikan konsep-konsep dasar seputar berpikir kritis atau critical thinking yang mudah dipahami dan dikuasi oleh peserta kegiatan.

4) Diskusi

Pada tahapan ini narasumber memberikan studi kasus untuk didiskusikan secara bersama. Pada tahapan ini juga peserta diberikan kesempatan untuk mengajukan pertanyaan seputar materi yang disajikan

5) Evaluasi

Evaluasi yang dilakukan dalam kegiatan ini dengan cara memberikan angket yang disebarkan kepada semua peserta. Evaluasi ini dilakukan untuk mengetahui kekurangan atau kendala dalam pelaksanaan agar kedepannya kegiatan serupa bisa dilakukan dengan lebih baik lagi.

\section{PELAKSANAAN DAN PEMBAHASAN}

SMA Citra Islami Cikupa adalah sekolah yang berada dibawah naungan Yayasan Islamic Village yang mengelola sekolah bernuansa Islami di Cikupa, Tangerang-Banten. Yayasan ini telah membuka semua jenjang pendidikan dari usia pra sekolah (PGTK), pendidikan dasar (SD) hingga pendidikan menengan pertama (SMP) dan tingkat pendidikan menengah atas (SMA). Kegiatan Latihan Dasar Kepemimpinan Siswa (LDKS) SMA Citra Islami dilakukan setiap tahun untuk mempersiapkan kader-kader calon pemimpin Organisasi Siswa Intra Sekolah atau OSIS. Pada tahun 202I ini, panitia penyelenggara LDKS bekerjasama dengan Tim Dosen Universitas Bina Bangsa melakukan kegiatan Pengabdian kepada Masyarakat dalam bentuk sosialisasi mengenai "Pentingnya Critical Thinking untuk Membangun Generasi Muda yang Kritis". Sebelum kegiatan sosialisasi dilakukan, tim dosen memilih salah seorang perwakilan sebagai narasumber dan mengumpulkan beberapa literatur yang mendukung penyusunan bahan kajian untuk dipresentasikan pada saat sosialisasi berlangsung. Tim menyiapkan materi yang disajikan dalam bentuk powerpoint (PPT) yang menarik, simpel dan interaktif. 
Sosialisasi Pentingnya Critical Thinking untuk Membangun Generasi Muda yang Kritis dalam kegiatan Latihan Dasar Kepemimpinan Siswa SMA Citra Islami Cikupa

Isnaini Mahuda' Miftahul Huda

Volume 1, No. 3, Desember 2021 hal. 210-215

DOI Artikel: 10.46306/jub.v1i3.38

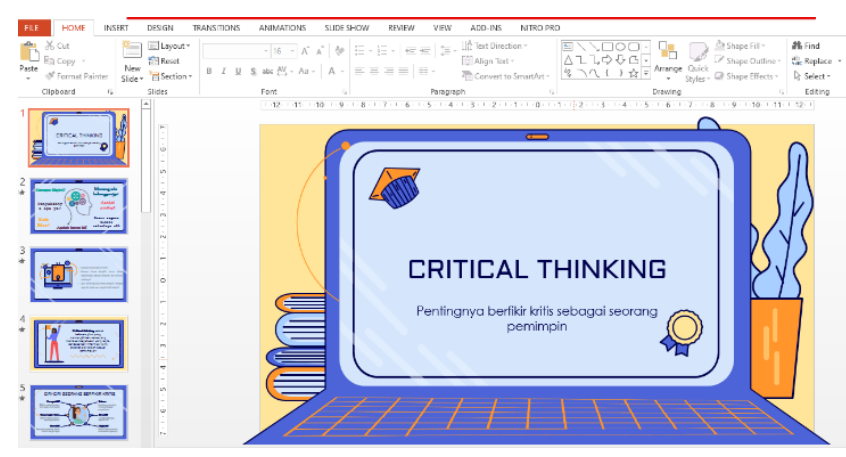

Gambar I. Materi yang disiapkan Tim Dosen dalam Bentuk PPT

Pelaksanaan kegiatan Pengabdian Kepada Masyarakat dalam bentuk sosialisasi ini menjadi rangkaian dari kegiatan Latihan Dasar Kepemimpinan Siswa SMA Citra Islami Serpong dan diikuti oleh para siswa/i calon pengurus Organisasi Siswa Intra Sekolah (OSIS). Pemaparan materi oleh narasumber yang merupakan perwakilan dari Tim Dosen dilakukan melalui ceramah yang diawali dengan pertanyaan “Mengapa kita harus berpikir kritis?" dan "Seberapa penting kemampuan berpikir kritis ini wajib dimiliki oleh seorang pemimpin?". Selanjutnya, narasumber membahas apa itu kemampuan berpikir kritis atau critical thinking, apa saja ciri-ciri seseorang yang memiliki kemampuan berpikir kritis, manfaat critical thinking, bagaimana melatih critical thinking dan alasan mengapa pentingnya critical thinking penting dimiliki oleh seorang pemimpin.

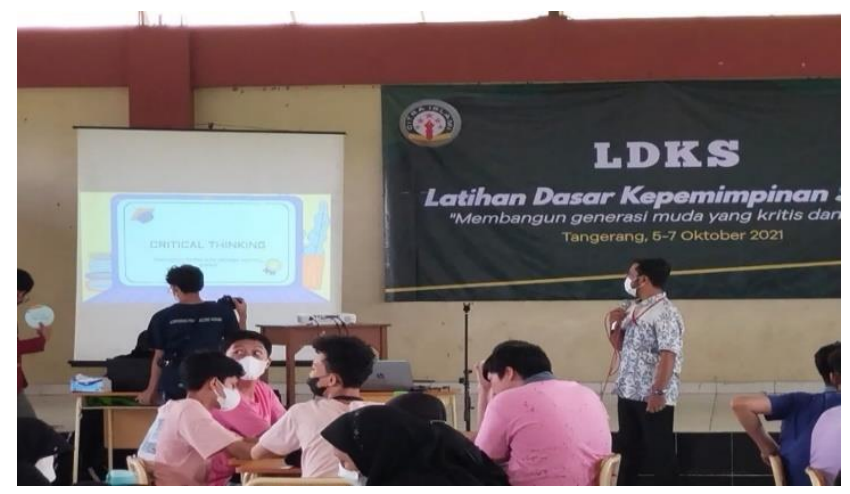

Gambar 2. Narasumber sedang Menyajikan Materi

Berikutnya pada sesi diskusi peserta kegiatan dibagi menjadi beberapa kelompok kecil dan diberikan beberapa contoh kasus untuk dapat mereka selesaikan dan diskusikan bersama. Setiap kelompok dapat memberikan tanggapan atau pandangannya terhadap kasus yang diberikan, Hal ini dilakukan untuk mengasah kemampuan berpikir kritis siswa. 
Sosialisasi Pentingnya Critical Thinking untuk Membangun Generasi Muda yang Kritis dalam kegiatan Latihan Dasar Kepemimpinan Siswa SMA Citra Islami Cikupa

Isnaini Mahuda' Miftahul Huda

Volume 1, No. 3, Desember 2021 hal. 210-215

DOI Artikel: 10.46306/jub.v1i3.38

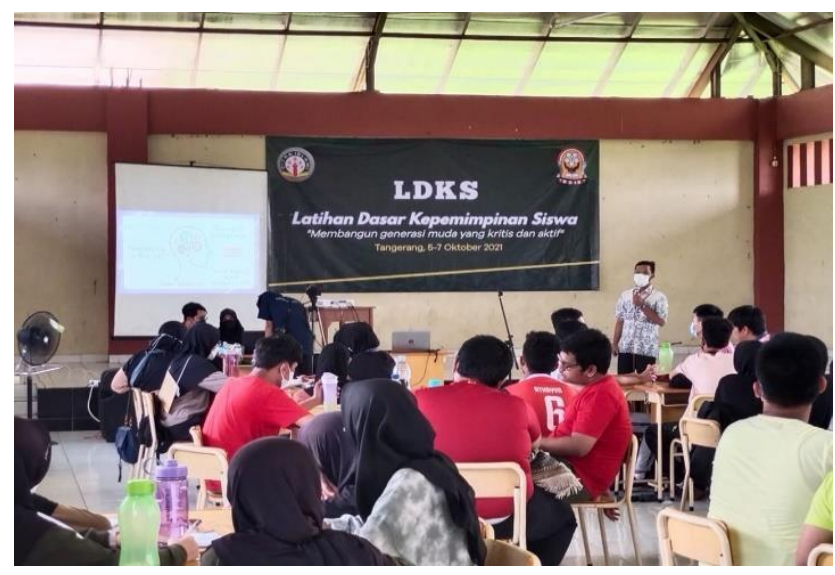

Gambar 3. Diskusi dengan Para Peserta Sosialisasi

Sesi terakhir adalah evaluasi yang dilakukan dengan menyebarkan angket kepada seluruh peserta sosialisasi. Peserta diminta untuk mengisi angket yang berisi pernyataan tentang pengetahuan yang telah diperoleh selama kegiatan sosialisasi dan masukan serta kritik saran yang konstruktif mengenai kegiatan ini. Diakhir kegiatan juga dilakukan serah terima plakat dan sertifikat dari panitia LDKS SMA Citra Islami Cikupa kepada perwakilan Tim Dosen yang menjadi narasumber sebagai bentuk ucapan terimakasih dan berharap kerjasama ini dapat terus berlangsung dikemudian hari.

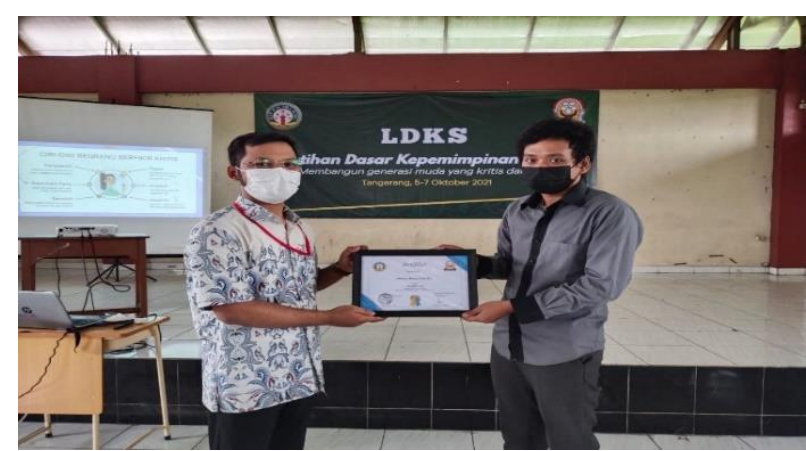

Gambar 4. Serah Terima Plakat dan Sertifikat dari Panitia kepada Perwakilan Tim

\section{KESIMPULAN DAN SARAN}

Dari kegiatan Pengabdian Kepada Masyarakat yang merupakan rangkaian dari kegiatan Latihan Dasar Kepemimpinan Siswa SMA Citra Islami Serpong memberikan beberapa kesimpulan, diantaranya yaitu:

I. sosialisasi mengenai pentingnya kemampuan berpikir kritis atau critical thinking berjalan dengan baik dan diikuti dengan sangat antusias oleh para siswa/i calon pengurus OSIS;

2. sosialisasi ini juga menjadi bekal bagi para siswa/i calon pengurus OSIS sebagai generasi muda calon pemimpin masa depan untuk terus mengasah kemampuan kritisnya. Adapun saran dari 
Sosialisasi Pentingnya Critical Thinking untuk Membangun Generasi Muda yang Kritis dalam kegiatan Latihan Dasar Kepemimpinan Siswa SMA Citra Islami Cikupa

Isnaini Mahuda' Miftahul Huda

Volume 1, No. 3, Desember 2021 hal. 210-215

DOI Artikel: 10.46306/jub.v1i3.38

kegiatan ini agar terus dilaksanakan secara konsisten dan berkelanjutan guna membentuk karakter-karakter yang dibutuhkan bagi seorang pemimpin yang baik.

\section{UCAPAN TERIMA KASIH (Jika ada)}

Tim mengucapkan terimakasih atas bantuan dan dukungan dari beberapa pihak diantaranya yaitu kepada Kepala Sekolah SMA Citra Islami Cikupa, Bapak/lbu Dewan Guru, para siswa panitia Latihan Dasar Kepemimpinan Siswa yang telah bekerjasama demi kelancaran acara ini. Tak lupa ucapan terimakasih kepada Rektor Universitas Bina Bangsa, jajaran Lembaga Penelitian dan Pengabdian (LPPM) Universitas Bina Bangsa yang telah memberikan izin kepada tim untuk melakukan kegiatan Pengabdian Kepada Masyarakat di SMA Citra Islami Cikupa, serta semua pihak yang telah membantu dan mensupport kegiatan ini sehingga kegiatan ini berjalan dengan lancar.

\section{DAFTAR PUSTAKA}

Bassham et al. (20II). Critical thinking: A student's introduction (4th ed.). New York: McGraw Hill.

Fredimento, A., Hoban, N., \& Bito, G. S. (2020). PKM LATIHAN KEPEMIMPINAN TINGKAT DASAR BAGI PENGURUS OSIS DAN PENGURUS KELAS SMA NEGERI WELAMOSA. Mitra Mahajana: Jurnal Pengabdian Masyarakat, I(I), I-I0. doi:I0.37478/mahajana.vliI.7I2

Jokiman, B. (2003). Dasar-Dasar Alkitabiah Pengembangan Kepemimpinan. Veritas: Jurnal Teologi Dan Pelayanan, 4(I), 87-106. doi:I0.3642I/veritas.v4il. 102

Masri, Z. A., \& Aqil, D. I. (20/8). Latihan Dasar Kepemimpinan untuk Pemuda Kelurahan Bedahan Kecamatan Sawangan Kota Depok. Jurnal PkM Pengabdian Kepada Masyarakat, I(02), 179. doi: 10.30998/jurnalpkm.vli02.2553

Oktavianti, N., Nariah, N., Imbron, I., Safiih, A. R., \& Nuraldy, H. L. (202I). PELATIHAN JIWA KEPEMIMPINAN KEPADA KOMUNITAS PENCINTA ALAM KELURAHAN PONDOK PUCUNG. DEDIKASI PKM, 2(2), I8I. doi:I0.32493/dedikasipkm.v2i2.976I

Patterson, F. (20II). Visualizing the Critical Thinking Process. Issues, 36-4I.

Wahyuni, S. (2016). Pengembangan Bahan Ajar IPA Untuk Meningkatkan Kemampuan Berpikir Kritis Siswa SMP. Jurnal materi dan pembelajaran fisika, 5(2), 47-52

Punto Wicaksono, melatih berfikir kritis dan manfaatnya, 202I, https://www.qubisa.com/article/melatihberpikir-kritis-dan-manfaatnya

World Economic Forum. 2016. The 10 Skills You Need To Thrive In The Fourth Industrial Revolution. (online). Tersedia dalam https:/www.weforum.org/agenda/2016/ 0l/the-10- skills-you-need-tothrive-in-the-fourth-industrial-revolution/. Diakses tanggal 4 Oktober 2021 